\section{OPEN ACCESS}

Edited by:

Donagh Berry,

Teagasc Food Research Centre,

Ireland

Reviewed by:

Jose Bento Sterman Ferraz,

University of São Paulo, Brazil

Juliana Petrini,

University of São Paulo, Brazil

Lucio Flavio Macedo Mota,

University of Padua, Italy

Rodrigo Savegnago,

Michigan State University, United States

Austin Michael Putz,

lowa State University, United States

*Correspondence:

Natalia Martín

n.p.martin@massey.ac.nz

Specialty section:

This article was submitted to

Livestock Genomics,

a section of the journal

Frontiers in Genetics

Received: 21 May 2021

Accepted: 27 August 2021

Published: 30 September 2021

Citation:

Martín N, Coleman L, López-Villalobos N, Schreurs N,

Morris S, Blair H, McDade J,

Back P and Hickson R (2021) Estimated Breeding Values of Beef

Sires Can Predict Performance of Beef-Cross-Dairy Progeny.

Front. Genet. 12:712715.

doi: 10.3389/fgene.2021.712715

\title{
Estimated Breeding Values of Beef Sires Can Predict Performance of Beef-Cross-Dairy Progeny
}

Natalia Martín ${ }^{1 *}$, Lucy Coleman ${ }^{1}$, Nicolás López-Villalobos ${ }^{1}$, Nicola Schreurs
',
Stephen Morris' ${ }^{1}$, Hugh Blair ${ }^{1}$, Julie McDade ${ }^{2}$, Penny Back ${ }^{1}$ and Rebecca Hickson ${ }^{1}$

${ }^{1}$ School of Agriculture and Environment, Massey University, Palmerston North, New Zealand, ${ }^{2}$ Greenlea Premier Meats Ltd., Hamilton, New Zealand

On average, half of the animal's estimated breeding value (EBV) is passed on to their progeny. However, it is not known how the performance of beef-cross-dairy cattle relates to the EBV of their beef sire. Such information is required to determine the genetic potential of beef sires selected based on existing EBV to be used on dairy cows in New Zealand. This study evaluated the relationship between the EBV of 30 Angus and 34 Hereford sires and the performance of their progeny for birth, growth, and carcass traits, via progeny testing of 975 beef-cross-dairy offspring born to dairy cows and grown on hill country pasture. Overall, BREEDPLAN EBV did predict progeny performance of the beef-crossdairy cattle from this study. Gestation length and birthweight increased with increasing sire EBV (mean $0.37-0.62$ days and $0.52-0.64 \mathrm{~kg}$, respectively, $p<0.05$ ). Age at weaning decreased with increasing sire EBV for liveweight at 200days (0.17-0.21 days per extra kilo of sire EBV, $p<0.05$ ) but sire EBV for liveweight at 200days had no effect on the liveweight of the progeny at 200days for either breed ( $p>0.05$ ). Liveweight increased with sire EBV for liveweight at 400,600, and 800days, by a similar amount for both breeds (between 0.23 and $0.42 \mathrm{~kg}$ increase in progeny liveweight per extra kilo of sire EBV, $p<0.05)$. The relationships were more inconsistent for carcass traits. For Hereford, carcass weight and eye muscle area increased with increasing sire EBV $\left(0.27 \mathrm{~kg}\right.$ and $0.70 \mathrm{~cm}^{2}$, respectively, $p<0.05$ ). For Angus, marble score increased by 0.10 with $1 \%$ extra in sire EBV for intramuscular fat $(p<0.05)$. Rib fat depth tended to increase with sire EBV for both breeds $(p<0.1)$. EBV derived from beef-breed data work in dairy-beef systems but maybe slightly less than the expected 0.5 units of performance per unit of EBV. New Zealand farmers should consider BREEDPLAN EBV when selecting sires to mate dairy cows or when buying beef-cross-dairy calves for beef production, to ensure the resulting calves are born safely and on time and then grow well to produce carcasses of suitable meat and fat composition.

Keywords: beef-on-dairy, carcass, crossbreeding, dairy-beef, genetic evaluation, gestation length, liveweight, progeny test 


\section{INTRODUCTION}

Estimated breeding values (EBV) are predictions of the relative genetic merit of an animal for a particular trait (Bourdon, 2014). The EBV for most beef cattle breeds in New Zealand for a range of economically important traits are produced by BREEDPLAN (Agricultural Business Research Institute, University of New England, Armidale, Australia), and these are breed-specific, meaning that although the traits analyzed are common among breeds, the values are not directly comparable across breeds because they are analyzed separately and have different reference points. The EBV are calculated based on phenotypic records of the animal and relatives, and records are limited to those from registered, purebred cattle, which are almost exclusively in bull-breeding nucleus herds. On average, half of the animal's EBV is passed on to the animal's progeny (Bourdon, 2014), and so, the regression of purebred progeny performance on sire EBV is expected to have a 0.5 slope. In addition, the expected regression between EBV and progeny performance will have a greater coefficient of determination $\left(\mathrm{R}^{2}\right)$ in traits with higher heritability.

The value of using EBV generated from data collected in purebred nucleus herds for selecting sires for use in a beef-ondairy crossbreeding scheme is less clear. Genetically superior animals are expected to perform better than inferior counterparts, particularly for weight, fat, and carcass traits (Afolayan et al., 2007; McIntyre et al., 2009). However, the genetic correlation between purebred and crossbred performance is lower than unity for many traits, due to genotype-by-genotype interaction, genotype-by-environment interaction, and different definition of traits (Wientjes and Calus, 2017). Crossbred animals will show some degree of heterosis and complementarity (Bourdon, 2014), phenotypic differences may appear from one environment to another for the same genotype (Charteris et al., 1997), and the same trait may be measured differently between animals and systems (Wientjes and Calus, 2017). If this occurs, the relative ranking or scaling of breeds, sires within each breed and their crossbred progeny may change in different locations or farm systems (Charteris et al., 1997; Morris and Smeaton, 2009; Santana et al., 2013), and this should be reflected in the relationship between the EBV of the sire and the actual performance of the progeny.

There are important differences between the beef and dairybeef systems in New Zealand, particularly around rearing, weaning, and finishing age. In a beef cow-calf system, calves are reared on their dams until weaning at a set date, around $5-7$ months of age [150-210 days and $180-240 \mathrm{~kg}$ liveweight (Geenty and Morris, 2017)]. In contrast in a dairy-beef system, calves are "artificially" reared on an allowance of $4-5 \mathrm{~L}$ of milk per day until weaning at a set weight, usually of $80-100 \mathrm{~kg}$ liveweight, achieved at 8-12 weeks of age [56-84days (Muir et al., 2000; Geenty and Morris, 2017)]. By their first autumn (around 200days), cattle from dairy-beef systems are much lighter than cattle from cow-calf systems, and this carries through to finishing. Consequently, beef-bred cattle have a target slaughter age of 18-22 months (Geenty and Morris, 2017), whereas beef-cross-dairy cattle are often slaughtered after their second winter to achieve target weights and avoid penalties associated with leanness and conformation (Bown et al., 2016).
Around $66 \%$ of the cattle slaughtered for beef production in New Zealand originate from dairy farms (Beef+Lamb New Zealand Economic Service, 2019; Ministry for Primary Industries, 2020; van Selm et al., 2021), and there is great industry interest to increase the proportion of surplus dairy calves that are reared for beef production, which will further raise this percentage. Thus, there is a strong need for genetic improvement of dairy-origin cattle in their potential for growth and carcass traits. To date, there is no information to quantify how useful the available EBV are to select beef bulls on their potential as terminal sires in a dairy-beef cattle system.

Previous studies in New Zealand (Martín et al., 2020, 2021; Coleman et al., 2021) have demonstrated considerable variation in performance among Angus and Hereford sires for birth, growth, and carcass traits. However, it was not explored how the sire performance related to their EBV. Given the considerable differences between beef and dairy-beef cattle systems mentioned above, it is possible that scaling or re-ranking of sires may occur. Such information is required in order to determine the genetic potential of beef sires selected based on existing EBV to be used on dairy cows, as these existing beef EBV may not be able to predict the performance of the crossbred progeny in a dairy-beef cattle system. Quantifying this relationship will assist with the development of future breeding programs for beef production in New Zealand, that include the use of beefon-dairy crossbreeding systems.

The hypothesis of this study was that the performance of beef-cross-dairy offspring is predicted by their sire's EBV. Therefore, this study aimed to evaluate the relationship between Angus and Hereford sires' EBV and the performance of their progeny for birth traits (gestation length and birthweight), growth at different ages (liveweight at 200, 400, 600, and 800 days of age), and carcass traits (carcass weight, eye muscle area, rib fat, and marble score), via progeny testing of beefcross-dairy offspring born to dairy cows and grown on hill country pasture for beef production.

\section{MATERIALS AND METHODOLOGY}

The animals reported here are a subset of animals for which growth and carcass traits were previously reported (Martín et al., 2020, 2021; Coleman et al., 2021). The animal study was conducted at Limestone Downs, near Port Waikato, New Zealand $\left(37^{\circ} 28^{\prime} \mathrm{S}, 174^{\circ} 45^{\prime} \mathrm{E}\right)$. The study and all handling procedures were reviewed and approved by the Massey University Animal Ethics Committee (15/65 and 18/50). Animals were processed commercially through Greenlea Premier Meats Ltd., Hamilton plant, New Zealand $\left(37^{\circ} 48^{\prime} \mathrm{S} 175^{\circ} 15^{\prime} \mathrm{E}\right)$, according to standard New Zealand industry practice (Animal and Animal Products Directorate, 2017).

\section{Animals and Management Sires}

The Angus and Hereford sires used in this experiment were selected from those nominated for progeny testing by cattle 
TABLE 1 | Estimated breeding values (EBV; mean $\pm S D$ ), with total range, accuracy (mean and range), and percentile bands for gestation length, liveweight (at birth, 200, 400, and 600 days of age), and carcass traits (carcass weight, eye muscle area, rib fat, and intramuscular fat), for 31 Angus and 34 Hereford sires.

\begin{tabular}{|c|c|c|c|c|c|c|c|c|c|c|}
\hline \multirow{2}{*}{ Trait } & \multicolumn{5}{|c|}{ Angus } & \multicolumn{5}{|c|}{ Hereford } \\
\hline & $\mathbf{n}$ & EBV & Range & Accuracy & Bands & $\mathbf{n}$ & EBV & Range & Accuracy & Bands \\
\hline Gestation length (days) & 31 & $-5.6 \pm 2.5$ & -10.1 to -0.4 & $89 \%(61-99)$ & 1-95th & 34 & $-1.5 \pm 3.4$ & -9.8 to 4.6 & $82 \%(45-99)$ & 0-100th \\
\hline Birthweight (kg) & 31 & $2.6 \pm 1.5$ & -0.3 to 5.7 & $92 \%(71-99)$ & 0-85th & 34 & $2.2 \pm 1.8$ & -2.5 to 6.8 & $93 \%(74-99)$ & 0-95th \\
\hline 200d weight (kg) & 31 & $41 \pm 9$ & 23 to 59 & 89\% (70-99) & 1-100th & 34 & $30 \pm 8$ & 18 to 48 & $91 \%(69-99)$ & 0-99th \\
\hline 400d weight (kg) & 31 & $78 \pm 13$ & 56 to 110 & 89\% (70-99) & 1-99th & 34 & $55 \pm 14$ & 31 to 79 & $91 \%(69-99)$ & 1-99th \\
\hline 600d weight (kg) & 31 & $101 \pm 18$ & 70 to 135 & 89\% (70-99) & 5-99th & 34 & $74 \pm 20$ & 35 to 114 & $91 \%(69-99)$ & 0-100th \\
\hline Carcass weight (kg) & 31 & $52 \pm 15$ & 26 to 80 & $81 \%(65-98)$ & 1-99th & 34 & $54 \pm 15$ & 25 to 84 & $82 \%(58-98)$ & 0-100th \\
\hline Eye muscle area $\left(\mathrm{cm}^{2}\right)$ & 31 & $5.2 \pm 2.2$ & -0.3 to 9.7 & $80 \%(62-98)$ & 1-100th & 34 & $3.1 \pm 2.0$ & 0.3 to 8.0 & $71 \%(50-96)$ & 0-100th \\
\hline Rib fat (mm) & 31 & $0.9 \pm 1.9$ & -2.0 to 6.1 & $82 \%(64-98)$ & 0-99th & 34 & $0.8 \pm 1.0$ & -1.8 to 2.7 & $74 \%(52-97)$ & 1-100th \\
\hline Intramuscular fat (\%) & 31 & $1.5 \pm 1.4$ & -2.1 to 4.4 & $78 \%(56-98)$ & 0-100th & 34 & $0.4 \pm 0.7$ & -1.0 to 2.0 & $73 \%(38-97)$ & 1-100th \\
\hline
\end{tabular}

n: number of sires used at mating; final number of sires included for data analysis: 30 Angus and 34 Hereford. Bands: fit of EBV within the percentile bands for 2018 born calves for each breed, where 0 is the top value and 100 is the bottom value for the trait. Updated in April 2020 from BREEDPLAN (Agricultural Business Research Institute, University of New

England, Armidale, Australia; https://breedplan.une.edu.au/)

breeders in New Zealand. Sires were selected on the basis of their EBV prior to each mating. The EBV are generated by BREEDPLAN for Angus and Hereford bulls within breed, as part of the trans-Tasman Angus or Hereford genetic evaluations. The EBV for each sire were obtained from the online databases of the New Zealand Angus and Hereford breed associations ${ }^{1}$ and have been previously reported (Martín et al., 2020, 2021; Coleman et al., 2021). The data collected in this experiment were not included for the calculation of the BREEDPLAN EBV for these sires, and so, EBV values are independent of the progeny results obtained.

Within each breed, a spread of birthweight, gestation length, and liveweight at 600 days of age (600d) EBV was achieved, except that birthweight EBV was restricted to the lightest 50\% of the breed at the time of selection to prevent potential calving difficulty. When similar sires were available, those with superior EBV for intramuscular fat (IMF) and eye muscle area (EMA) were selected. There were a total of 31 Angus and 34 Hereford bulls used over 2 breeding seasons. Mean and range of EBV for birth, liveweight, carcass, and meat traits by breed of sire are presented in Table $\mathbf{1}$.

\section{Dams}

Lactating, mixed-aged cows (over 2 years old and multiparous) were individually inseminated with semen from the selected sires. Cows were predominantly Holstein-Friesian or HolsteinFriesian-cross-Jersey crossbred. Semen was rotationally allocated to mating days and randomly allocated to cows in estrus on each mating day, to achieve random mating with semen from all sires distributed throughout the mating period. Cows were bred for 63 days in 2015 and 54days in 2016.

\section{Progeny}

Angus-sired and Hereford-sired singleton calves born to mixedaged dairy cows in spring $2016(n=512)$ and $2017(n=463)$ were included in the study. Mean birth date was August 6,

${ }^{1}$ https://breedplan.une.edu.au/
2016, (SD 18 days) and August 8, 2017 (SD 16 days). Calves born in the previous $24 \mathrm{~h}$ were collected daily at approximately $10 \mathrm{am}$ and brought to the calf rearing shed.

In 2016, early-born calves $(n=119)$ were sent to a commercial calf rearer (approximately $140 \mathrm{~km}$ southeast of the farm, $37^{\circ}$ 56 'S $175^{\circ} 39^{\prime} \mathrm{E}$ ) at a minimum of 7 days old. These calves were reared on an allowance of $3 \mathrm{~L}$ of milk/head twice a day for the first 3 weeks and then $4 \mathrm{~L}$ of milk/head/day until weaning. Calves were fed colostrum or whole milk for 6 weeks and a 50:50 mixture of stored colostrum and milk powder (Ancalf, NZAgBiz, Hamilton, New Zealand) for the remainder of the time until weaning. All calves were offered ad libitum meal [16\% Crude Protein $(\mathrm{CP})]$ and had no access to pasture during the pre-weaning period. These calves were weighed weekly and weaned at a minimum of $75 \mathrm{~kg}$ liveweight, before returning to the farm of birth at around $100 \mathrm{~kg}$.

The remainder of the calves born in 2016, and all calves born in 2017, were reared on the dairy farm. These calves were reared on an allowance of 4 liters of milk/head/day of whole milk, and calf meal (17-20\% CP) was offered ad libitum during the transition from milk to pasture. Calves were weighed every $1-3$ weeks and weaned at a minimum of $85 \mathrm{~kg}$ liveweight.

The resulting mean weaning liveweight of all calves in this study was $93.0 \mathrm{~kg}$ (SD 7.0). Once weaned, calves were moved from the dairy farm to the adjacent sheep and beef hill country farm. Male calves were castrated before 4 months of age.

At 4 months of age (December of 2016 and 2017), at a mean age of 128.7 days (SD 16.8), and a mean liveweight of $123.3 \mathrm{~kg}$ (SD 15.5), calves were allocated into 6 grazing herds based on liveweight (light, intermediate, and heavy) and sex (heifer and steer) and balanced for sire so that, where possible, all sires were represented in each grazing herd within a year. In total, there were 12 grazing herds ( 2 years $\times 2$ sexes $\times 3$ liveweight groups) and animals remained in those herds throughout the experiment until slaughter. All cattle were grazed on summer-dry hill country pasture under commercial conditions (Martín et al., 2020). Any animals that died or were removed from their contemporary group due to illness or escaping were removed from the 
experiment at that time, but previous measurements were included in the study.

Each grazing herd was slaughtered as a complete group on the same day, when the mean liveweight reached the slaughter target liveweight of $500 \mathrm{~kg}$ for heifers and $600 \mathrm{~kg}$ for steers (Martín et al., 2021). Heifers were slaughtered at a mean age of 819 days of age (range 693-923, 27 months old) and $519 \mathrm{~kg}$ (SD 37) liveweight, while steers were slaughtered at a mean age of 885 days of age (range 821-954, 29 months old) and $613 \mathrm{~kg}$ (SD 43) liveweight.

\section{Measurements}

\section{Birth Traits}

Birth traits were recorded for all calves, whether alive or dead at the time of collection. Parentage was assigned using DNA parentage assignment (Zoetis, Dunedin, New Zealand). Gestation length (days) was calculated as the difference between insemination date and birth date. Insemination date was the date on which the DNA-assigned dam was inseminated using semen from the DNA-assigned sire. Date of birth was recorded as the date which the calf was brought into the calf rearing shed.

Birthweight was recorded on arrival to the calf rearing shed, prior to being fed, using a weigh crate (Prattley Industries Ltd., Temuka, New Zealand; weight scales model EziWeigh7i, Tru-Test, Auckland, New Zealand; load bars MP600, Tru-Test, Auckland, New Zealand).

\section{Growth Traits}

Prior to weaning, calves were weighed every $1-3$ weeks as they approached weaning weight, and on each occasion, calves over $85 \mathrm{~kg}$ were weaned $(75 \mathrm{~kg}$ at the commercial rearer). Date and liveweight at weaning were recorded for each calf. Age at weaning was calculated as the difference between birth and weaning dates.

After weaning, calves were weighed on the farm using a weigh crate at a minimum of 2-monthly intervals, as described in Martín et al. (2020). Short-term fluctuations in liveweight were smoothed out by calculating centered moving averages of three liveweight records per animal using the Expand procedure (SAS 9.4, SAS Institute Inc., Cary, NC, United States). Predicted liveweights for each animal at 200d, 400d, 600d, and $800 \mathrm{~d}$ were calculated by interpolation of the smoothed liveweight curves.

\section{Carcass Traits}

After slaughter, the bodies were dressed to New Zealand commercial specifications (Animal and Animal Products Directorate, 2017), and hot carcass weight $(\mathrm{kg})$ was recorded prior to the carcasses going into the chiller (Martín et al., 2021). Carcasses were chilled $\left(4 \pm 1^{\circ} \mathrm{C}\right)$ overnight, and the following morning, one side of the carcass was cut between the 12th and 13th rib to expose the eye muscle (M. longissimus thoracis) for in-chiller assessment of rib fat thickness ( $\mathrm{mm}$ ), eye muscle area (EMA in $\mathrm{cm}^{2}$ ), and marbling score. Marbling was scored on a scale from 0 (nil) to 9 (abundant) according to the AUS-MEAT/MSA reference standards (AUS-MEAT Limited, 2018).

\section{Statistical Analysis \\ Data Cleaning}

Sires with a minimum of five progeny records were included in the analysis for that trait, resulting in 1 Angus sire excluded for all traits, 1 Angus sire excluded for all traits except birthweight, and 1 Hereford sire excluded for marble score.

\section{Progeny Mean Calculations}

Linear mixed models were used to estimate least-squares means for progeny groups using the statistical package SAS 9.4 (SAS Institute Inc. 2013, Cary, NC, United States).

The models for birth traits (gestation length and birthweight) included the fixed effect of sire within breed and the random effect of contemporary group. Contemporary group $(n=8$, with 101 to 149 animals in each group) was defined as the group of animals born in the same year $(n=2,2016$ and 2017), of the same sex $(n=2$, heifer and steer) that were progeny of sires of the same breed ( $n=2$, Angus and Hereford).

The model for weaning age included the fixed effect of sire within breed and the random effect of contemporary group. Contemporary group ( $n=12$, with 25 to 117 animals in each group) was defined as the group of animals born in the same year $(n=2,2016$ and 2017), of the same sex $(n=2$, heifer and steer) that were progeny of sires of the same breed $(n=2$, Angus and Hereford) and were reared at the same location ( $n=2$, commercial rearer and dairy farm). Weaning weight was fitted as a covariate for weaning age.

The models for liveweight (at 200d, 400d, 600d, and 800d) included the fixed effect of sire within breed and the random effect of contemporary group. Contemporary group $(n=24$, with 25 to 47 animals in each group) was defined as the group of animals grazing in the same herd $(n=12,2$ years $\times 2$ sexes $\times 3$ liveweight groups), that were progeny of sires of the same breed ( $n=2$, Angus and Hereford).

The models for carcass traits (carcass weight, EMA, rib fat depth and marble scores) included the fixed effect of sire within breed and the random effect of contemporary group. Contemporary group ( $n=24$, with 24 to 41 animals in each group) was the same as that for liveweight. Age deviation at slaughter (within contemporary group) was fitted as a covariate for carcass weight. Carcass weight was fitted as a covariate for EMA, rib fat depth, and marble score.

\section{Regressions of Progeny Means on Sire EBV}

Least-squares means of beef-cross-dairy progeny groups for birth, growth, and carcass traits were regressed against sire EBV using linear regressions, to test the slope of the regression to be greater than 0 . The regressions with $95 \%$ confidence intervals were done separately for each breed of sire and were weighted by the number of progeny of each sire for each trait. Sire EBV for liveweight at $200 \mathrm{~d}$ was used to predict least-squares means of the progeny groups for weaning age. Sire EBV for liveweight at $600 \mathrm{~d}$ was used to predict least-squares means of the progeny 
groups for liveweight at $800 \mathrm{~d}$. Sire EBV for IMF was used to predict least-squares means of the progeny groups for marble score.

\section{RESULTS}

The total number of sires and progeny, and mean and range of the least-square means of beef-cross-dairy progeny groups for birth, liveweight, and carcass traits is presented in Table 2.

\section{Regression of Progeny Means on Sire EBV for Birth Traits}

Gestation length increased by 0.37 or 0.62 days for a 1-day increase in sire EBV for Angus and Hereford sires, respectively $(p<0.05$, Table 3; Figure 1). Birthweight increased by 0.64 or $0.52 \mathrm{~kg}$ per $1 \mathrm{~kg}$ extra in sire EBV for Angus and Hereford sires, respectively $(p<0.05)$.

\section{Regression of Progeny Means on Sire EBV for Growth Traits}

Age at weaning decreased by 0.17 or 0.21 days per $1 \mathrm{~kg}$ extra in sire EBV for liveweight at 200d for Angus and Hereford, respectively ( $p<0.05$, Table 4; Figure 2). However, sire EBV for liveweight at $200 \mathrm{~d}$ had no effect on the liveweight of the progeny at $200 \mathrm{~d}$ for either breed $(p>0.05)$. Liveweight increased with EBV at $400 \mathrm{~d}, 600 \mathrm{~d}$, and $800 \mathrm{~d}$, by a similar amount for both breeds $(p<0.05)$.

\section{Regression of Progeny Means on Sire EBV for Carcass Traits}

For Hereford, carcass weight increased by $0.27 \mathrm{~kg}$ per $1 \mathrm{~kg}$ extra in sire EBV $(p<0.05$, Table 5; Figure 3), EMA increased by $0.70 \mathrm{~cm}^{2}$ with $1 \mathrm{~cm}^{2}$ extra in sire EBV $(p<0.05)$, and rib fat depth tended to increase with sire EBV $(p<0.1)$, but there was no relationship between marble score and sire EBV for IMF $(p>0.05)$. For Angus, marble score increased by 0.10 with $1 \%$ extra in sire EBV for IMF ( $p<0.05$, Table 5; Figure 3), while carcass weight and rib fat depth tended to increase with sire EBV $(p<0.1)$, and there was no relationship between EMA and sire EBV $(p>0.05)$.

\section{DISCUSSION}

Sire EBV had a positive association with progeny gestation length and birthweight for both breeds, indicating that choosing sires with lower EBV will reduce the gestation length and birthweight of calves. For gestation length, the association was stronger for the Hereford sires than the Angus sires $\left(\mathrm{R}^{2}=57\right.$ and $40 \%$, respectively), because there was a greater spread and more sires in the top $5 \%$ of the breed. The good match between EBV and actual performance indicates that these are likely to be the same trait being assessed in both purebred Angus or Hereford cattle and beef-cross-dairy cattle. Gestation length records are readily obtained in dairy herds

TABLE 2 | Number of sires and progeny, mean $( \pm \mathrm{SD})$, and range of the least-squares means of beef-cross-dairy progeny groups for birth (gestation length and birthweight), growth (age at weaning and liveweight (LWT) at 200, 400, 600, and 800 days of age), and carcass traits (carcass weight, eye muscle area (EMA), rib fat depth, and marble score), for 30 Angus and 34 Hereford sires.

\begin{tabular}{|c|c|c|c|c|c|c|c|c|}
\hline \multirow{2}{*}{ Progeny mean } & \multicolumn{4}{|c|}{ Angus } & \multicolumn{4}{|c|}{ Hereford } \\
\hline & $n$ sires & $n$ progeny & Mean \pm SD & Range & $n$ sires & $n$ progeny & Mean \pm SD & Range \\
\hline Gestation length (days) & 29 & 405 & $279.8 \pm 1.5$ & 276.4 to 282.9 & 34 & 455 & $282.9 \pm 2.8$ & 276.1 to 289.0 \\
\hline LWT at birth (kg) & 30 & 463 & $36.2 \pm 1.6$ & 33.6 to 40.2 & 34 & 512 & $37.3 \pm 1.9$ & 33.7 to 43.1 \\
\hline Age at weaning (days) & 29 & 407 & $82.2 \pm 3.3$ & 76.8 to 88.0 & 34 & 458 & $80.9 \pm 4.3$ & 70.2 to 88.2 \\
\hline LWT at $200 d(\mathrm{~kg})$ & 29 & 406 & $158.4 \pm 5.3$ & 148.4 to 168.5 & 34 & 460 & $158.7 \pm 5.1$ & 150.1 to 172.3 \\
\hline LWT at 400d (kg) & 29 & 394 & $284.1 \pm 7.9$ & 269.5 to 299.3 & 34 & 457 & $283.4 \pm 8.8$ & 264.1 to 298.3 \\
\hline LWT at 600d (kg) & 29 & 379 & $425.2 \pm 13.6$ & 401.9 to 465.1 & 34 & 446 & $426.0 \pm 12.0$ & 402.5 to 447.8 \\
\hline LWT at 800d (kg) & 29 & 329 & $502.5 \pm 14.2$ & 475.7 to 540.7 & 34 & 397 & $505.4 \pm 15.8$ & 470.4 to 544.1 \\
\hline Carcass weight (kg) & 29 & 369 & $276.4 \pm 9.2$ & 258.5 to 304.8 & 34 & 429 & $277.0 \pm 9.3$ & 260.7 to 295.6 \\
\hline $\mathrm{EMA}\left(\mathrm{cm}^{2}\right)$ & 29 & 367 & $73.8 \pm 3.0$ & 66.8 to 79.0 & 34 & 428 & $73.2 \pm 3.7$ & 66.9 to 82.9 \\
\hline Rib fat depth (mm) & 29 & 366 & $7.2 \pm 1.2$ & 4.8 to 9.2 & 34 & 428 & $7.7 \pm 1.5$ & 4.9 to 11.3 \\
\hline Marble score & 29 & 331 & $1.1 \pm 0.3$ & 0.5 to 1.6 & 33 & 384 & $0.8 \pm 0.3$ & 0.2 to 1.5 \\
\hline
\end{tabular}

TABLE 3 | Estimates of regression coefficients (intercept and slope) of least-squares means of beef-cross-dairy progeny groups for birth traits (gestation length and birthweight) on corresponding sire EBV, for 30 Angus and 34 Hereford sires.

\begin{tabular}{|c|c|c|c|c|c|c|c|c|}
\hline \multirow{2}{*}{ Progeny mean } & \multicolumn{4}{|c|}{ Angus } & \multicolumn{4}{|c|}{ Hereford } \\
\hline & Intercept & Slope & $p$-value & $\mathbf{R}^{2}$ & Intercept & Slope & $p$-value & $\mathbf{R}^{2}$ \\
\hline Gestation length (days) & $281.9 \pm 0.5$ & $0.37 \pm 0.09$ & $<0.001$ & 0.40 & $283.8 \pm 0.3$ & $0.62 \pm 0.10$ & $<0.001$ & 0.57 \\
\hline Birthweight $(\mathrm{kg})$ & $34.4 \pm 0.5$ & $0.64 \pm 0.15$ & $<0.001$ & 0.39 & $36.2 \pm 0.4$ & $0.52 \pm 0.14$ & $<0.001$ & 0.32 \\
\hline
\end{tabular}

$R^{2}$ : coefficient of determination. 

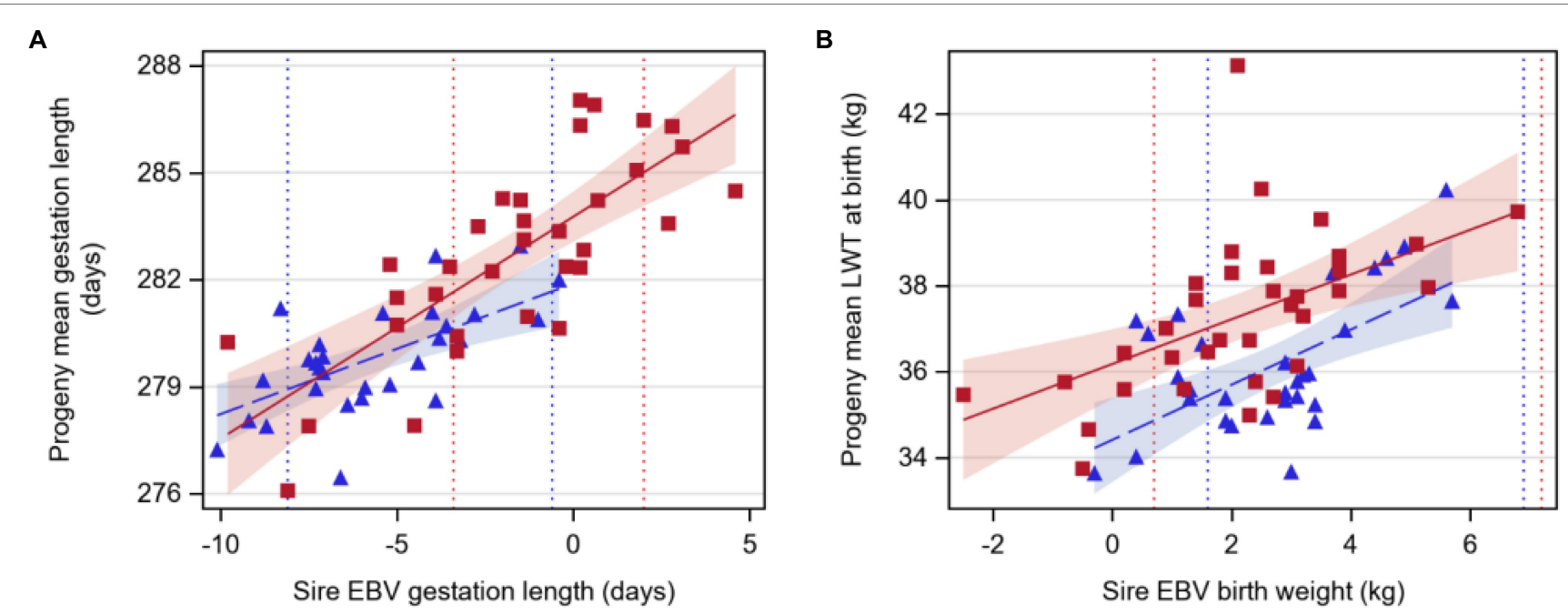

FIGURE 1 | Regression of least-squares means of beef-cross-dairy progeny groups on sire EBV for: (A) gestation length (days) and (B) liveweight at birth (LWT, kilograms). Individual sires are represented by one data point (Angus, $\mathbf{\Delta}$ triangles, $n=30$; Hereford, $\mathbf{m}$ red squares, $n=34$ ), and the regression lines by breed are indicated by lines (Angus, __ _ dashed line; Hereford, __ solid line). Shaded areas indicate 95\% confidence intervals for the expected regression line for each breed (Angus, $\square$ blue; Hereford, 1 red). Colored dotted lines indicate 5 and 95th EBV percentiles for 2018 born calves within the BREEDPLAN population for each breed (Angus, ... blue; Hereford, ... red). Details of regression coefficients are presented in Table 3.

TABLE 4 | Estimates of regression coefficients (intercept and slope) of least-squares means of beef-cross-dairy progeny groups for growth traits (age at weaning and liveweight at 200, 400, 600, and 800 days of age) on corresponding sire EBV for liveweight, for 29 Angus and 34 Hereford sires.

\begin{tabular}{|c|c|c|c|c|c|c|c|c|}
\hline \multirow{2}{*}{ Progeny mean } & \multicolumn{4}{|c|}{ Angus } & \multicolumn{4}{|c|}{ Hereford } \\
\hline & Intercept & Slope & $p$-value & $\mathbf{R}^{2}$ & Intercept & Slope & $p$-value & $\mathbf{R}^{2}$ \\
\hline Age at weaning (days) ${ }^{\ddagger}$ & $89.6 \pm 2.6$ & $-0.17 \pm 0.06$ & 0.009 & 0.23 & $87.8 \pm 2.7$ & $-0.21 \pm 0.08$ & 0.015 & 0.17 \\
\hline LWT at $200 \mathrm{~d}(\mathrm{~kg})$ & $153.5 \pm 4.6$ & $0.12 \pm 0.11$ & 0.291 & 0.04 & $156.0 \pm 3.7$ & $0.08 \pm 0.11$ & 0.482 & 0.02 \\
\hline LWT at 400d (kg) & $265.6 \pm 8.1$ & $0.23 \pm 0.10$ & 0.029 & 0.16 & $267.9 \pm 5.7$ & $0.28 \pm 0.10$ & 0.008 & 0.20 \\
\hline LWT at 600d (kg) & $388.4 \pm 11.5$ & $0.36 \pm 0.11$ & 0.003 & 0.28 & $401.8 \pm 6.6$ & $0.32 \pm 0.08$ & $<0.001$ & 0.32 \\
\hline LWT at $800 \mathrm{~d}(\mathrm{~kg})^{*}$ & $459.5 \pm 11.9$ & $0.42 \pm 0.11$ & 0.001 & 0.33 & $479.0 \pm 9.5$ & $0.36 \pm 0.12$ & 0.006 & 0.21 \\
\hline
\end{tabular}

$R^{2}$ : coefficient of determination. ${ }^{\ddagger}$ Progeny mean for age at weaning was regressed with sire EBV for weight at 200d. ${ }^{\ddagger}$ Progeny mean for $L W T$ at $800 d$ was regressed with sire EBV for weight at 600d.

through the widespread use of artificial breeding in New Zealand [over $70 \%$ of dairy cows (LIC and DairyNZ, 2020)], and this information could be used to provide information on the sires to assist in evaluating genetic merit for gestation length.

For birthweight, the restriction during selection to the lighter half of each breed meant that the sires included in this study were biased toward the lighter end of the breed, and consequently, the associations of progeny and sire EBV were low-to-moderate for both breeds $\left(\mathrm{R}^{2}=32-39 \%\right)$. Regardless, the associations were positive and close to the expected 0.5 slope, and so, BREEDPLAN EBV can be used to manage birthweight when selecting beef sires for use in the dairy industry. A similar approach has been used in other studies to avoid calving difficulties (Berry et al., 2019; Eriksson et al., 2020).

The earlier weaning age for sires with greater EBV for liveweight at $200 \mathrm{~d}$ is the result of faster pre-weaning growth of these calves. It should be noted that birthweight was not related to $200 \mathrm{~d}$ weight EBV ( $p>0.05$, data not shown), so the earlier weaning age was not simply a birthweight effect. Weaning age can have important implications at the dairy farm, where there is an explicit cost involved in milk feeding. The findings also align with the industry recommendations for calf rearing in New Zealand, based predominantly on Holstein-Friesian bull calves, where calves that grow faster are typically weaned earlier (Muir et al., 2001, 2002).

The lack of association between sire EBV and progeny liveweight at $200 \mathrm{~d}$ was foreseeable given the differences in breeds (beef vs. beef-cross-dairy) and rearing systems used to calculate sire EBV and progeny liveweight. Angus and Hereford sires' EBV for liveweight at 200d are derived from weaning weight records on purebred beef calves, reared in cow-calf systems where calves are reared on their mother until $200 \mathrm{~d}$ (Geenty and Morris, 2017). This EBV measures pre-weaning growth, which is influenced by the calf's growth potential and feeding intensity, and the dam's milk production (Asheim et al., 2016; Geenty and Morris, 2017). Recent results from a Beef Progeny Test in New Zealand, where 984 progeny of 52 sires 

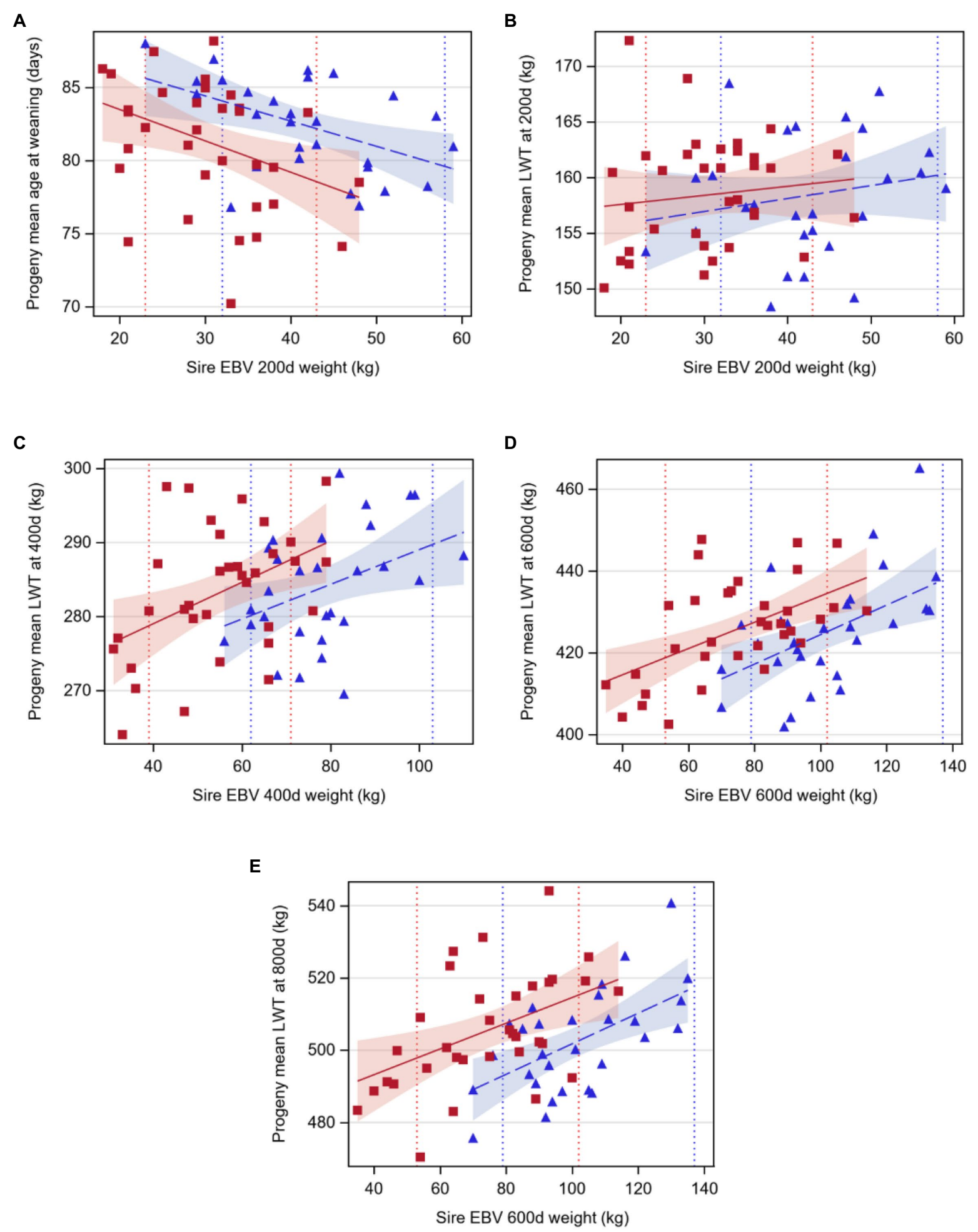

FIGURE 2 | Regression of least-squares means of beef-cross-dairy progeny groups on sire EBV for: (A) age at weaning (days) on weight at 200 days (kilograms), (B) liveweight at 200 days (LWT, kilograms), (C) liveweight at 400 days (LWT, kilograms), (D) liveweight at 600 days (LWT, kilograms), and (E) liveweight at 800 days on weight at 600 days (LWT, kilograms). Individual sires are represented by one data point (Angus, $\Delta$ blue triangles, $n=29$; Hereford, $\bullet$ red squares, $n=34$ ), and the regression lines by breed are indicated by lines (Angus, _ _ dashed line; Hereford, __ solid line). Shaded areas indicate $95 \%$ confidence intervals for the expected regression line for each breed (Angus, 1 blue; Hereford, red). Colored dotted lines indicate 5 and 95th EBV percentiles for 2018 born calves within the BREEDPLAN population for each breed (Angus, ... blue; Hereford, ... red). Details of regression coefficients are presented in Table 4. 
TABLE 5 | Estimates of regression coefficients (intercept and slope) of least-squares means of beef-cross-dairy progeny groups for carcass traits (carcass weight, eye muscle area (EMA), rib fat depth, and marble score) on corresponding sire EBV, for 29 Angus and 34 Hereford sires.

\begin{tabular}{|c|c|c|c|c|c|c|c|c|}
\hline \multirow{2}{*}{ Progeny mean } & \multicolumn{4}{|c|}{ Angus } & \multicolumn{4}{|c|}{ Hereford } \\
\hline & Intercept & Slope & $p$-value & $\mathbf{R}^{2}$ & Intercept & Slope & $p$-value & $\mathbf{R}^{2}$ \\
\hline Carcass weight (kg) & $266.4 \pm 5.4$ & $0.18 \pm 0.10$ & 0.079 & 0.11 & $262.0 \pm 5.6$ & $0.27 \pm 0.10$ & 0.008 & 0.20 \\
\hline $\mathrm{EMA}\left(\mathrm{cm}^{2}\right)$ & $72.5 \pm 1.4$ & $0.24 \pm 0.26$ & 0.356 & 0.03 & $71.1 \pm 1.1$ & $0.70 \pm 0.30$ & 0.025 & 0.15 \\
\hline Rib fat depth (mm) & $7.0 \pm 0.2$ & $0.20 \pm 0.11$ & 0.070 & 0.12 & $7.2 \pm 0.3$ & $0.44 \pm 0.25$ & 0.091 & 0.09 \\
\hline Marble score ${ }^{\ddagger}$ & $0.93 \pm 0.07$ & $0.10 \pm 0.04$ & 0.012 & 0.21 & $0.81 \pm 0.06$ & $0 \pm 0.07$ & 0.993 & 0.00 \\
\hline
\end{tabular}

$R^{2}$ : coefficient of determination. ${ }^{*}$ Progeny mean for marble score was regressed with sire EBV for intramuscular fat.

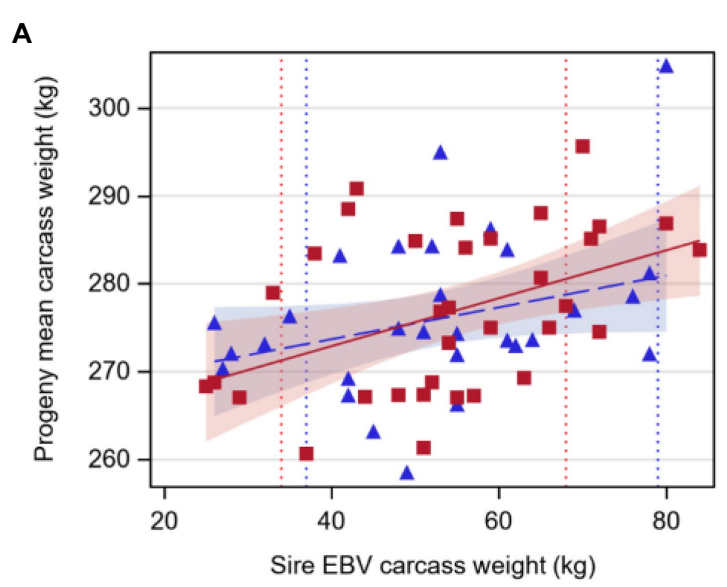

C

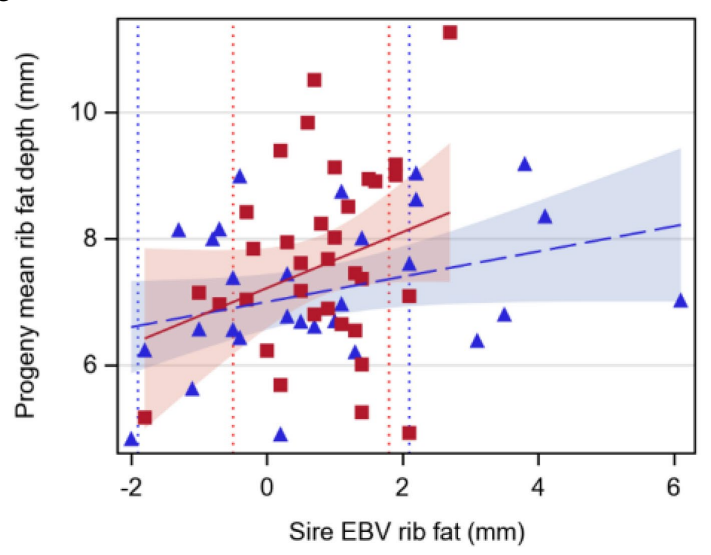

B

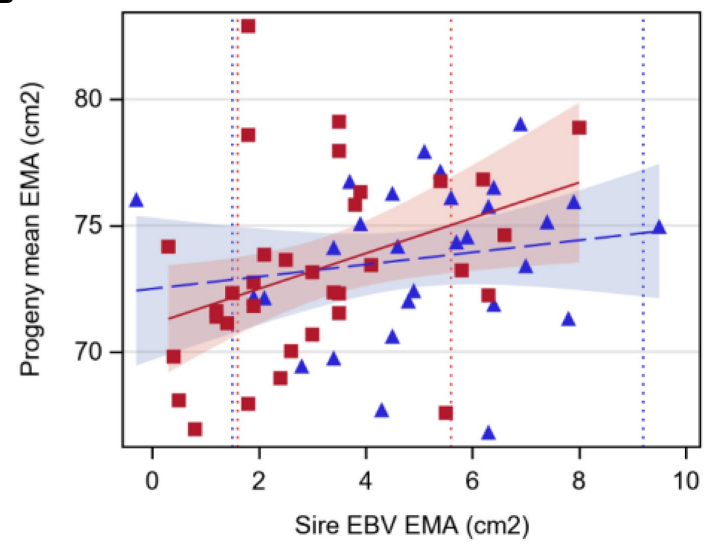

D

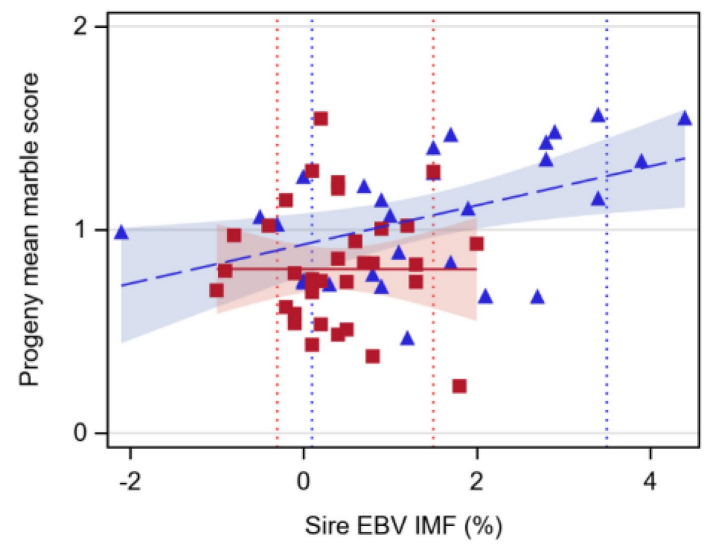

FIGURE 3 | Regression of least-squares means of beef-cross-dairy progeny groups on sire EBV for: (A) carcass weight (kg), (B) eye muscle area (EMA, cm²), (C) rib fat depth (mm), and (D) marble score (on intramuscular fat, IMF \%). Individual sires are represented by one data point (Angus, $\mathbf{\Delta}$ blue triangles, $n=29$; Hereford, a red squares, $n=34$ ), and the regression lines by breed are indicated by lines (Angus, _ _ dashed line; Hereford, _ solid line). Shaded areas indicate 95\% confidence intervals for the expected regression line for each breed (Angus, $\square$ blue; Hereford, $\square$ red). Colored dotted lines indicate 5 and 95th EBV percentiles for 2018 born calves within the BREEDPLAN population for each breed (Angus, ... blue; Hereford, ... red). Details of regression coefficients are presented in Table $\mathbf{5}$.

of Angus, Hereford, Stabilizer, Simmental, and Charolais breeds were considered for growth and carcass traits, showed that $1 \mathrm{~kg}$ extra in the sire EBV for $200 \mathrm{~d}$ weight could predict $0.49 \mathrm{~kg}$ increase in liveweight of the calves at weaning at 200d (Beef+Lamb New Zealand Genetics, 2019). In that study, mean liveweight at weaning was $206.1 \mathrm{~kg}$. In comparison, calves from the present experiment were removed from their dams within $24 \mathrm{~h}$ of birth, and group fed on an allowance of $4-6 \mathrm{~L}$ of milk/head/day until weaning. Weaning occurred at a fixed liveweight, rather than a fixed age as it happens in cow-calf rearing systems. This meant that lighter or slower-growing calves got fed milk for more days to achieve the target weaning weight and so may have had an advantage compared with faster-growing calves, effectively creating a genotype-by-environment interaction that favored the slower-growing calves. The unequal treatment of calves perhaps prevented a good assessment of the growth 
potential at $200 \mathrm{~d}$ weight of the calves, but it reflects the reality of the dairy-beef systems and highlights the importance of including weaning age in the assessed traits.

After weaning, the calves in this study went on a pasturebased diet, which was of low quality over the summer [metabolizable energy (ME) of 9.2 MJ per kilogram of dry matter (kgDM), CP 12.6 \%DM (Martín et al., 2020)]. Low-quality pasture likely restricted animal performance, because calves grew at an average of $0.55 \mathrm{~kg} / \mathrm{d}$ from weaning at $81.5-200 \mathrm{~d}$, compared with $0.69 \mathrm{~kg} / \mathrm{d}$ pre-weaning $(0-81.5 \mathrm{~d})$. Young cattle require pasture with greater than $11.4 \mathrm{MJME} / \mathrm{kgDM}$ and covers higher than 2,200 $\mathrm{kgDM}$ per hectare to grow at the target rate of $1 \mathrm{~kg} / \mathrm{d}$ (Geenty and Morris, 2017) and to express their genetic potential for growth, or alternatively when pasture quality is poor, they require supplementary concentrate feed to increase liveweight gain (Pettigrew et al., 2017). Therefore, there was no maternal influence through milk production on calf growth, and liveweight at $200 \mathrm{~d}$ was the result of postweaning liveweight gain restricted by the poor-quality diet. Additionally, the prolonged artificial rearing of the slowergrowing calves in this dairy-beef system enabled them to achieve similar liveweights to faster-growing calves up to $200 \mathrm{~d}$. Consequently, 200d liveweight EBV is a useful predictor of weaning age in a dairy-beef system, but is not a good indicator of liveweight at $200 \mathrm{~d}$.

By 400d, liveweight of calves was again reflective of their sire's $\mathrm{EBV}$, although the regression coefficient was less than the 0.41 and 0.45 reported for $400 \mathrm{~d}$ and $600 \mathrm{~d}$ weight in the New Zealand Beef Progeny Test mentioned earlier (Beef + Lamb New Zealand Genetics, 2019). When comparing the beef-crossdairy progeny liveweights at $800 \mathrm{~d}$ with sire EBV for liveweight at $600 \mathrm{~d}$, the association was much stronger. The increased regression coefficient with increasing age likely reflected the decreasing influence of the longer milk-feeding period of slowgrowing calves in early life. Additionally, the cattle were closer to mature size by $800 \mathrm{~d}$, having grown relatively slow during their life $(0.43 \mathrm{~kg} / \mathrm{d}$ from $200 \mathrm{~d}$ to $800 \mathrm{~d})$. The low-quality pasture would have restricted animal performance (Burke et al., 2002) and likely resulted in a smaller increase in progeny performance with increasing sire EBV than may have been achieved in an environment that provided greater quantity and quality of feed, without necessarily changing the ranking of the sires (Hammami et al., 2009; McIntyre et al., 2009).

Increasing sire EBV for carcass weight and EMA was associated with increases in the respective traits in the progeny of the Hereford sires in this experiment, but this was not the case for the Angus sires. For both breeds, sire EBV had a positive trend on rib fat depth. The $\mathrm{R}^{2}$ value was low for both breeds, but this result was generally consistent with the result from the Beef Progeny Test previously mentioned (Beef + Lamb New Zealand Genetics, 2019). One possible explanation for the better predictive ability of liveweight compared with any carcass EBV is that there is much more phenotypic information available to predict the EBV for liveweight, and the data to derive these EBV have been recorded for a longer period of time (Cundiff et al., 2007). This was reflected in the lower accuracy of the carcass vs. liveweight EBV of the sires used:
Accuracy for liveweight EBV ranged from 69 to 99\% (mean $89 \%$ for Angus and 91\% for Hereford sires), while accuracies for carcass weight EBV ranged from 58 to $98 \%$ (mean $81 \%$ for Angus and $82 \%$ for Hereford sires) and for EMA EBV from 50 to $98 \%$ (mean $80 \%$ for Angus and $71 \%$ for Hereford sires). Further, sire EBV for EMA, as well as rib fat depth and IMF, are based on ultrasound measurements on live animals at 18 months of age as well as measurements on the carcass for related animals processed in Australia (Johnston et al., 1999; BREEDPLAN, 2015), whereas the progeny group means presented here were based only on measurements collected at processing at around 28 months of age. Even though the genetic correlation of ultrasound and carcass measures is moderate to strong (Reverter et al., 2000), there is considerable variation in the values of the correlations [e.g., for Angus and Hereford breeds, rib fat depth $r_{g}=0.02$ to 0.99 , EMA $r_{g}=0.16$ to 0.94 , IMF $r_{g}=0.28$ to 0.93 (Reverter et al., 2000; Su et al., 2017)]. This will inevitably affect the accuracy of the EBV (agreement between true and predicted values) and highlights the need to improve the information gathered to generate the EBV for carcass traits. Yet, precision (correct ranking of animals) is more important than accuracy for genetic evaluations (Herring and Kemp, 2001). Therefore, differences in the ability of the EBV to predict progeny performance for carcass traits were somewhat expected.

Sire EBV for IMF had a low-to-moderate positive association with marble score for the Angus sires in this experiment (slope $=0.10 ; \mathrm{R}^{2}=21 \%$ ), but not for the Hereford sires. Angus sires used in the experiment had a wider range of EBV for IMF compared with Hereford sires (6.5 and 3.0\% IMF spread of EBV, respectively, although this is a reflection of the spread within each breed rather than a difference in sampling). Moreover, Angus-sired progeny had higher marble scores compared with Hereford-sired cattle [0.21 scores greater, $p<0.05$ (Martín et al., 2021)], even though the range of scores was 0-3 for both breeds. Accordingly, more Angus sires had higher marble scores than Hereford sires in this experiment. This result may be explained by the physiological age at slaughter and the breeders' emphasis on marbling. Even though both Angus and Hereford are considered early maturing breeds (Purchas, 2003; Bartoň et al., 2006), Angus cattle are known to reach physiological maturity at an earlier age (Chambaz et al., 2001) and to exhibit higher marbling than other beef breeds (Thonney, 2015). Given that the cattle in this study were slaughtered at a common age (which depended on the contemporary group reaching a mean target weight, rather than selecting those animals with the right finishing attributes, such as good fat cover over the back and tail), then it is possible that Hereford cattle were not as physiologically mature as the Angus cattle. This is supported by the fact that Hereford-sired cattle had longer carcasses than Angus-sired animals in this study $[2.0 \mathrm{~cm}$ difference, $p<0.05$ (Martín et al., 2021)], indicating that Hereford were larger-framed and less mature compared with Angus cattle, at the same carcass weight (Thonney, 2015). In addition, New Zealand Angus breeders have been putting emphasis on marbling through the AngusPure Index. To qualify for 
AngusPure grading premiums, ${ }^{2}$ heifers and steers require a minimum marbling score of 2 . Even though cattle that are half dairy cannot qualify for this premium, greater marble scores can be achieved in beef-cross-dairy animals by selecting sires that rank highly in this breeding index.

One limitation of this experiment was that the maternal breed was not accounted for because there was scarce information on the dams. Dams were predominantly Holstein-Friesian or Holstein-Friesian-cross-Jersey crossbred. A greater proportion of Holstein-Friesian would produce heavier calves with faster growth rates and heavier carcasses, while a greater proportion of Jersey would produce smaller animals with slower growth rates, lighter carcasses, and higher marbling (Barton et al., 1994; Buchanan and Lenstra, 2015; Bown et al., 2016; Handcock et al., 2018). Nevertheless, it is unlikely that there would be a bias in the data from this study because sires were randomly allocated to cows, and analysis by Coleman et al. (2019) showed that the cows in this experiment had similar liveweights and milk production regardless of the sire they were bred to.

A further potential limitation is that sires used in this experiment were not a random sample, as they were selected for the project based on their EBV so that, within each breed, a spread of birthweight (restricted to the lighter 50\%), gestation length, and liveweight at $600 \mathrm{~d}$ was achieved. With greater selection intensity (smaller proportion of bulls selected from the total available), then the expected correlation between EBV in different systems decreases (Charteris, 1995). However, the selection to achieve a spread of EBV creates a more representative population than selection for the best EBV, and the EBV of the sires of both breeds did cover most of the range of possible EBV for each growth and carcass trait [spanning at least the percentiles 1-99th for most, except for Angus gestation length (1-95th), birthweight $\left(0-85^{\text {th }}\right)$, and liveweight at 600d (5-99th), and Hereford birthweight (0-95th)].

Lastly, there was variation in the EBV accuracy, which ranged between 45 and $99 \%$ for birth traits, $69-99 \%$ for growth traits, $50-98 \%$ for carcass size traits, and $38-98 \%$ for carcass fat traits. The traits examined also vary in their published heritability estimates, namely, $0.44-0.68$ for gestation length, $0.25-0.45$ for birthweight, $0.12-0.70$ for liveweight, $0.23-0.54$ for carcass weight, $0.20-0.47$ for EMA, 0.25-0.45 for rib fat depth, 0.15-0.49 for IMF, and 0.17-0.48 for marbling (Angus New Zealand, n.d.; Baker et al., 1975, 1990; Van Vleck et al., 1992; Gregory et al., 1995; Reverter et al., 2000, 2003a,b; Winkelman and Spelman, 2001; Rios Utrera and Van Vleck, 2004; Afolayan et al., 2007; Warner et al., 2010; Amer et al., 2016; Su et al., 2017). Lower accuracy of the EBV, in addition to each sire having a low number of progeny (5-25 progeny for most traits), implies that both the available BREEDPLAN EBV and the measured phenotypic results could be an over- or underrepresentation of the real sire merit. Errors in the independent variable, in this case EBV, can cause significant bias in estimated regression coefficient (Robinson, 2005), reducing the regression slope. On the other hand, increasing progeny numbers evaluated per sire can increase the accuracy and correlation between

${ }^{2}$ https://www.anguspure.co.nz/ sire EBV in different environments (Blair and Garrick, 1994). For example, assuming the genetic correlation of a trait across environments is 1.0 and a heritability of the trait of 0.25 , increasing the number of progeny tested from 20 to 50 would increase the correlation between EBV for different environments from 0.38 to 0.76 (Charteris, 1995). Nevertheless, the number of progeny used in this study is comparable with other progeny tests done in New Zealand (Baker et al., 1975; Beef+Lamb New Zealand Genetics, 2019), and the large number of sires used allows for mendelian sampling effects on individual progeny group means.

\section{CONCLUSION}

Overall, BREEDPLAN EBV did predict progeny performance of the beef-cross-dairy cattle from this study, indicating that EBV derived from beef-breed data work in dairy-beef systems but may result in slightly less than the expected 0.5 unit increase in performance per unit of EBV. This was particularly true for birth and growth traits, except for 200d liveweight for both Angus and Hereford breeds. The relationships were less consistent for carcass traits. Hereford sires had better associations with carcass size traits, while Angus sires had better associations with carcass fat traits. Although EBV for carcass traits are currently useful, improvement in the information used to generate them is still required to increase their accuracy and ability to predict progeny performance. Beef-cross-dairy cattle could also be included in joint genetic evaluations, given the strong dairy component in the cattle slaughtered in New Zealand. New Zealand farmers should consider BREEDPLAN EBV when selecting sires to mate to dairy cows or when buying beef-cross-dairy calves for beef production, to ensure the resulting calves are born safely and on time, and then grow well to produce carcasses of suitable meat and fat composition.

\section{DATA AVAILABILITY STATEMENT}

The raw data supporting the conclusions of this article will be made available on request to the corresponding author.

\section{ETHICS STATEMENT}

The animal study was reviewed and approved by Massey University Animal Ethics Committee (Palmerston North, New Zealand). Written informed consent was obtained from the owners for the participation of their animals in this study.

\section{AUTHOR CONTRIBUTIONS}

RH, PB, NL-V, LC, and NM: conceptualization. NM, LC, RH, NL-V, PB, HB, NS, SM, and JM: methodology and writing - review and editing. NM and LC: investigation, data curation, 
and software. NM, LC, RH, and NL-V: formal analysis. NM and $\mathrm{RH}$ : validation, NM: visualization and writing - original draft preparation. RH, PB, NL-V, NS, SM, HB, and JM: supervision. NM, LC, RH, PB, and JM: project administration. $\mathrm{RH}, \mathrm{PB}$, and JM: resources. $\mathrm{RH}$ and JM: funding acquisition. All authors contributed to the article and approved the submitted version.

\section{FUNDING}

This research was funded by Beef and Lamb New Zealand Genetics (DBPT2015). The primary author was funded by a R\&D Fellowship Grant between Callaghan Innovation and Greenlea Premier Meats Limited-Massey University (GPMES1601/PROP50347-FELLOW-GPMES) and the second author was funded by a Massey University Doctoral Scholarship. The contributions

\section{REFERENCES}

Afolayan, R. A., Pitchford, W. S., Deland, M. P., and McKiernan, W. A. (2007). Breed variation and genetic parameters for growth and body development in diverse beef cattle genotypes. Animal 1, 13-20. doi: 10.1017/ S1751731107257933

Amer, P., Stachowicz, K., Jenkins, G., and Meier, S. (2016). Short communication: estimates of genetic parameters for dairy fertility in New Zealand. J. Dairy Sci. 99, 8227-8230. doi: 10.3168/jds.2015-10429

Angus New Zealand (n.d.). Heritabilities of traits in Angus Group BREEDPLAN [Online]. Available at: http://angusnz.com/cattle/technical/ebvs/heritability/ [Accessed 21 June, 2018].

Animal and Animal Products Directorate (2017). Red Meat Code of Practice Chapter 5: Slaughter and Dressing. (Wellington, New Zealand: Ministry for Primary Industries)

Asheim, L. J., Johnsen, J. F., Havrevoll, Ø., Mejdell, C. M., and Grøndahl, A. M. (2016). The economic effects of suckling and milk feeding to calves in dual purpose dairy and beef farming. Rev. Agric. Food Environ. Stud. 97, 225-236. doi: 10.1007/s41130-016-0023-4

AUS-MEAT Limited (2018). Handbook of Australian Beef Processing. Queensland, Australia: AUS-MEAT Limited.

Baker, R. L., Carter, A. H., and Beatson, P. R. (1975). Progeny testing Angus and Hereford bulls for growth performance. Proc. N. Z. Soc. Anim. Prod. 35, 103-111.

Baker, R., Carter, A., Morris, C., and Johnson, D. (1990). Evaluation of eleven cattle breeds for crossbred beef production: performance of progeny up to 13 months of age. Anim. Sci. 50, 63-77. doi: 10.1017/S0003356100004475

Barton, R. A., Donaldson, J. L., Barnes, F. R., Jones, C. F., and Clifford, H. J. (1994). Comparison of Friesian, Friesian-Jersey cross, and Jersey steers in beef production. N. Z. J. Agric. Res. 37, 51-58. doi: 10.1080/00288233. 1994.9513040

Bartoň, L., Řehák, D., Teslík, V., Bureš, D., and Zahrádková, R. (2006). Effect of breed on growth performance and carcass composition of Aberdeen Angus, Charolais, Hereford and Simmental bulls. Czeh J. Anim. Sci. 51, 47-53. doi: 10.17221/3908-CJAS

Beef+Lamb New Zealand Economic Service (2019). "Compendium of New Zealand Farm Facts 2019" in Farm Facts. 43rd ed (Wellington, New Zealand: Beef+Lamb New Zealand)

Beef+Lamb New Zealand Genetics (2019). "Sire report: cohort 2" in Beef Progeny Test (New Zealand: Dunedin)

Berry, D. P., Amer, P. R., Evans, R. D., Byrne, T., Cromie, A. R., and Hely, F. (2019). A breeding index to rank beef bulls for use on dairy females to maximize profit. J. Dairy Sci. 102, 10056-10072. doi: 10.3168/jds.2019-16912 of the C. Alma Baker Trust NZ Ltd., Angus NZ, and NZ Hereford Association are gratefully acknowledged. The funders approved the design of the study but had no role in the collection, analyses or interpretation of data, in the writing of the manuscript, or in the decision to publish the results.

\section{ACKNOWLEDGMENTS}

The authors gratefully acknowledge Limestone Downs farm staff, Greenlea Premier Meats staff and Massey University technical staff for their valuable support and assistance in data collection. The data presented in this manuscript have previously appeared in the dissertations of Coleman (2020) and Martín (2021), that will be available online through the university repository at Massey Research Online (https://mro. massey.ac.nz/).

Blair, H. T., and Garrick, D. J. (1994). How relevant are current and emerging genetic technologies to the beef breeding cow? Proc. N. Z. Soc. Anim. Prod. 54, 337-344.

Bourdon, R.M. (2014). Understanding Animal Breeding. Harlow, England: Pearson Education Limited.

Bown, M. D., Muir, P. D., and Thomson, B. C. (2016). Dairy and beef breed effects on beef yield, beef quality and profitability: a review. N. Z. J. Agric. Res. 59, 174-184. doi: 10.1080/00288233.2016.1144621

BREEDPLAN (2015). A basic guide to BREEDPLAN EBVs. Armidale, Australia: International Beef Recording Scheme.

Buchanan, D. S., and Lenstra, J. A. (2015). "Breeds of cattle" in The Genetics of Cattle. eds. D. J. Garrick and A. Ruvinsky. 2nd ed (Wallingford, United Kingdom: CAB International), 33-66.

Burke, J. L., Waghorn, G. C., and Chaves, A. V. (2002). Improving animal performance using forage-based diets. Proc. N. Z. Soc. Anim. Prod. 62, 267-272.

Chambaz, A., Morel, I., Scheeder, M. R. L., Kreuzer, M., and Dufey, P. A. (2001). Characteristics of steers of six beef breeds fattened from eight months of age and slaughtered at a target level of intramuscular fat: I, growth performance and carcass quality. Arch. Anim. Breed. 44, 395-412. doi: 10.5194/ aab-44-395-2001

Charteris, P. L. (1995). Selection for Beef Cattle Carcass and Meat Quality Traits. Thesis presented in partial fulfilment of the requirements for the degree of Master of Agricultural Science in Animal Science, Massey University.

Charteris, P. L., Garrick, D. J., and Morris, S. T. (1997). Sire by finishing environment interactions for carcass and meat quality traits in beef cattle. Proc. N. Z. Soc. Anim. Prod. 57, 192-195.

Coleman, L.W. (2020). The Use of High Genetic Merit Angus and Hereford Bulls in a New Zealand Dairy Herd. Thesis presented in partial fulfilment of the requirements for the degree of Doctor of Philosophy in Animal Science, Massey University.

Coleman, L. W., Back, P. J., Blair, H. T., Lopez-Villalobos, N., and Hickson, R. E. (2019). Milk production and rebreeding performance of mixed-aged dairy cows mated to Angus or Hereford bulls. N. Z. J. Anim. Sci. Prod. 79, 144-148.

Coleman, L., Back, P., Blair, H., López-Villalobos, N., and Hickson, R. (2021). Sire effects on birth weight, gestation length, and pre-weaning growth of beef-cross-dairy calves: a case study in New Zealand. Dairy 2, 385-395. doi: 10.3390/dairy2030030

Cundiff, L. V., Thallman, R. M., van Vleck, L. D., Bennett, G. L., and Morris, C. A. (2007). Cattle breed evaluation at the US Meat Animal Research Centre and implications for commercial beef farmers. Proc. N. Z. Soc. Anim. Prod. $67,9-17$.

Eriksson, S., Ask-Gullstrand, P., Fikse, W. F., Jonsson, E., Eriksson, J.-A., Stålhammar, H., et al. (2020). Different beef breed sires used for crossbreeding with Swedish dairy cows - effects on calving performance and carcass traits. Livest. Sci. 232, 103902. doi: 10.1016/j.livsci.2019.103902 
Geenty, K., and Morris, S. (eds.). (2017). Guide to New Zealand Cattle Farming. Wellington, New Zealand: Beef+Lamb New Zealand.

Gregory, K. E., Cundiff, L. V., and Koch, R. M. (1995). Genetic and phenotypic (co)variances for growth and carcass traits of purebred and composite populations of beef cattle. J. Anim. Sci. 73, 1920-1926. doi: 10.2527/1995.7371920x

Hammami, H., Rekik, B., and Gengler, N. (2009). Genotype by environment interaction in dairy cattle. Biotechnol. Agron. Soc. Environ. 13, 155-164.

Handcock, R. C., Lopez-Villalobos, N., McNaughton, L. R., Back, P. J., Edwards, G. R., and Hickson, R. E. (2018). Live weight and growth of Holstein-Friesian, Jersey and crossbred dairy heifers in New Zealand. $N$. Z. J. Agric. Res. 62, 173-183. doi: 10.1080/00288233.2018.1465984

Herring, W., and Kemp, D. (2001). The use of ultrasound technology in genetic selection decisions. Proc. XVII Range Beef Cow Sym. 82, 44-53.

Johnston, D. J., Tier, B., Graser, H.-U., and Girard, C. (1999). Introducing BREEDPLAN Version 4.1. Proc. Assoc. Advmt. Anim. Genet. 13, 193-196.

LIC and DairyNZ (2020). New Zealand Dairy Statistics 2019-20. Hamilton, New Zealand: Livestock Improvement Corporation Limited \& DairyNZ Limited.

Martín, N. P. (2021). The Effect of Sire on Growth and Meat Production of Beef-Cross-Dairy Cattle in New Zealand. Thesis presented in partial fulfilment of the requirements for the degree of Doctor of Philosophy in Animal Science, Massey University.

Martín, N., Schreurs, N., Morris, S., López-Villalobos, N., McDade, J., and Hickson, R. (2020). Sire effects on post-weaning growth of beef-cross-dairy cattle: a case study in New Zealand. Animals 10, 2313-2324. doi: 10.3390/ ani10122313

Martín, N., Schreurs, N., Morris, S., López-Villalobos, N., McDade, J., and Hickson, R. (2021). Sire effects on carcass of beef-cross-dairy cattle: a case study in New Zealand. Animals 11, 636-648. doi: 10.3390/ani11030636

McIntyre, B. L., Tudor, G. D., Read, D., Smart, W., Della Bosca, T. J., Speijers, E. J., et al. (2009). Effects of growth path, sire type, calving time and sex on growth and carcass characteristics of beef cattle in the agricultural area of Western Australia. Anim. Prod. Sci. 49, 504-514. doi: 10.1071/EA08180

Ministry for Primary Industries (2020). Livestock slaughter statistics [Online]. Available at: http://www.mpi.govt.nz/news-and-resources/open-data-andforecasting/agriculture (Accessed 11 November, 2020).

Morris, S. T., and Smeaton, D. (eds.). (2009). Profitable Farming of Beef Cows. Hamilton, New Zealand: NZ Sheep and Beef Council, Meat and Wool New Zealand.

Muir, P. D., Fugle, C. J., and Ormond, A. W. A. (2002). Calf rearing using a once-a-day milk feeding system: current best practice. Proc. N. Z. Grass. Assoc. 64, 21-24. doi: 10.33584/jnzg.2002.64.2469

Muir, P. D., Fugle, C. J., Smith, N. B., and Ormond, A. W. A. (2001). A comparison of bull beef production from Friesian type and selected Jersey type calves. Proc. N. Z. Grass. Assoc. 63, 203-207. doi: 10.33584/jnzg.2001.63.2410

Muir, P. D., Nieuwenhuis, G., Smith, N. B., and Ormond, A. W. A. (2000). A comparison of rearing systems for dairy beef calves. Proc. N. Z. Grass. Assoc. 62, 9-12. doi: 10.33584/jnzg.2000.62.2385

Pettigrew, E. J., Morris, S. T., Back, P. J., Kenyon, P. R., Berry, J., Donald, A. J., et al. (2017). Growth of weaned Friesian bull calves on a herb sward or with concentrate supplementation during late summer and early autumn. N. Z. J. Agric. Res. 60, 70-79. doi: 10.1080/00288233.2016.1259641

Purchas, R. (2003). "Factors affecting carcass composition and beef quality" in Profitable Beef Production in New Zealand. New Zealand Beef Council Report. ed. D. Smeaton (Wellington, New Zealand: Ministry of Primary Industries), 124-152.

Reverter, A., Johnston, D. J., Ferguson, D. M., Perry, D., Goddard, M. E., Burrow, H. M., et al. (2003a). Genetic and phenotypic characterisation of animal, carcass, and meat quality traits from temperate and tropically adapted beef breeds. 4. Correlations among animal, carcass, and meat quality traits. Aust. J. Agric. Res. 54, 149-158. doi: 10.1071/AR02088

Reverter, A., Johnston, D. J., Graser, H. U., Wolcott, M. L., and Upton, W. H. (2000). Genetic analyses of live-animal ultrasound and abattoir carcass traits in Australian Angus and Hereford cattle. J. Anim. Sci. 78, 1786-1795. doi: $10.2527 / 2000.7871786 x$

Reverter, A., Johnston, D. J., Perry, D., Goddard, M. E., and Burrow, H. M. (2003b). Genetic and phenotypic characterisation of animal, carcass, and meat quality traits from temperate and tropically adapted beef breeds. 2 . Abattoir carcass traits. Aust. J. Agric. Res. 54, 119-134. doi: 10.1071/ AR02086

Rios Utrera, A., and Van Vleck, L. D. (2004). Heritability estimates for carcass traits of cattle: a review. Genet. Mol. Res. 3, 380-394

Robinson, D. L. (2005). Accounting for bias in regression coefficients with example from feed efficiency. Livest. Prod. Sci. 95, 155-161. doi: 10.1016/j. livprodsci.2004.12.017

Santana, M. L., Eler, J. P., Cardoso, F. F., Albuquerque, L. G., and Ferraz, J. B. S. (2013). Phenotypic plasticity of composite beef cattle performance using reaction norms model with unknown covariate. Animal 7, 202-210. doi: $10.1017 /$ S1751731112001711

Su, H., Golden, B., Hyde, L., Sanders, S., and Garrick, D. (2017). Genetic parameters for carcass and ultrasound traits in Hereford and admixed Simmental beef cattle: accuracy of evaluating carcass traits1. J. Anim. Sci. 95, 4718-4727. doi: 10.2527/jas2017.1865

Thonney, M. L. (2015). "Genetics of growth and body composition," in The Genetics of Cattle. 2nd Edn. eds. D. J. Garrick and A. Ruvinsky. (Wallingford, United Kingdom: CAB International), 523-543.

van Selm, B., de Boer, I. J. M., Ledgard, S. F., and van Middelaar, C. E. (2021). Reducing greenhouse gas emissions of New Zealand beef through better integration of dairy and beef production. Agric. Syst. 186:102936. doi: 10.1016/j.agsy.2020.102936

Van Vleck, L. D., Hakim, A. F., Cundiff, L. V., Koch, R. M., Crouse, J. D., and Boldman, K. G. (1992). Estimated breeding values for meat characteristics of crossbred cattle with an animal model. J. Anim. Sci. 70, 363-371. doi: $10.2527 / 1992.702363 \mathrm{x}$

Warner, R. D., Greenwood, P. L., Pethick, D. W., and Ferguson, D. M. (2010). Genetic and environmental effects on meat quality. Meat Sci. 86, 171-183. doi: $10.1016 /$ j.meatsci.2010.04.042

Wientjes, Y. C. J., and Calus, M. P. L. (2017). BOARD INVITED REVIEW: the purebred-crossbred correlation in pigs: A review of theory, estimates, and implications. J. Anim. Sci. 95, 3467-3478. doi: 10.2527/jas.2017. 1669

Winkelman, A., and Spelman, R. (2001). Selection for reduced gestation length in New Zealand dairy cattle. Proc. Assoc. Advmt. Anim. Breed. Genet. 14, 63-66.

Conflict of Interest: JM is employed by Greenlea Premier Meats Ltd. (Hamilton, New Zealand).

The remaining authors declare that the research was conducted in the absence of any commercial or financial relationships that could be construed as a potential conflict of interest.

Publisher's Note: All claims expressed in this article are solely those of the authors and do not necessarily represent those of their affiliated organizations, or those of the publisher, the editors and the reviewers. Any product that may be evaluated in this article, or claim that may be made by its manufacturer, is not guaranteed or endorsed by the publisher.

Copyright () 2021 Martín, Coleman, López-Villalobos, Schreurs, Morris, Blair, McDade, Back and Hickson. This is an open-access article distributed under the terms of the Creative Commons Attribution License (CC BY). The use, distribution or reproduction in other forums is permitted, provided the original author(s) and the copyright owner(s) are credited and that the original publication in this journal is cited, in accordance with accepted academic practice. No use, distribution or reproduction is permitted which does not comply with these terms. 